\title{
CREATIVITY AND INNOVATION FOR CHILDREN: PRESENTATION AND FIRST EXPERIMENT OF NEW (SERIOUS) GAME
}

\author{
Clara LIBE, Alexandre GRENOUILLAT, Jean LAGOUTTE, Camille JEAN and Nicolas \\ MARANZANA \\ Arts et Metiers Institute of Technology, LCPI, HESAM Université, F-75013 Paris, France
}

\begin{abstract}
Serious games are not only games for an entertaining purpose, they are also designed to teach concepts in a playful way. These games are more and more popular in the family, school and work environments. A previous work classified existing serious games published in the Design Society database and showed that there are few games in the field of creativity and innovation designed for children. The purpose of this article is therefore to present a new serious game to address this point and to experiment it with children. The experiment was realized with 2 groups of pupils: 25 pupils in third grade ( $\sim 8$ years old) and 24 pupils in fifth grade ( 10 years old). The results show that both groups enjoy the game but have difficulties in understanding its "serious" part in the amount of time available. We conclude on recommendations for the design of serious game on creativity and innovation for children.
\end{abstract}

Keywords: Engineering education, innovation, creativity, serious game, children

\section{INTRODUCTION}

One of the key issues for companies lies in having people that understand the full technique of creativity and innovation. A previous article (Cortes Sobrino et al, 2017) highlighted the fact that it exists few games focusing on children that give them a 'hands-on experience" on creativity and innovation techniques. The main purpose of this paper is to present a new educational game on this topic. Section 2 introduces the identified need using a 3-inputs matrix (public, purpose, skills) classifying existing serious games present in the Design Society database. Section 3 describes the created serious game. Section 4 shows the methodology proposed to analyse the experimentation. Results are explained in section 5. A short discussion and some recommendations are proposed in the concluding section.

\section{EDUCATIONAL GAMES}

All educational games are games designed with educational purposes (Susi, 2007). They can take a variety of forms, from card games to board games and video games and contribute to the acquisition of knowledge or skills in every stage of life (childhood, student life, professional life) (Breuer, 2010; Djaouti, 2011). They are used because they can provide enjoyment, passionate involvement, structure, motivation, ego gratification, adrenaline, creativity, social interaction and emotion in the game itself while the learning takes place (Prensky, 2001).

Cortes Sobrino et al (2017) used a 3-inputs matrix to classify the different educational games on design and innovation present in the Design Society database. This matrix was adapted of the G/P/S model of Djaouti et al. (2011b). The 3 categories classify games in term of:

- Public: Targeted people are divided in three categories: "children", "student", and "professional". A child educational game will be more game-playing while a professional educational game will be more conventional with more formal orientations.

- Purpose: It describes the utility function of the game. Three groups compose it: "spread a message" (inform people about a subject), « educate » (learning by doing) and "train" (coach people about a subject with a virtual training before a real doing) (Michael et al, 2005).

- Skill: They are classified using the C.D.I.O. model (Crawley, 2002) as Conceive (ability to plan mentally the image of a product or service), Design (ability to model the imagined product), Implement (the ability to materialize a product turning a virtual product into a real one) and Operate 
(ability to add value to a product or service, to industrialize it and to benefit from it).

Figure 1 shows 17 games about creativity and innovation found in the Design Society database classified in the 3-inputs matrix. One game can be classified in more than one box.

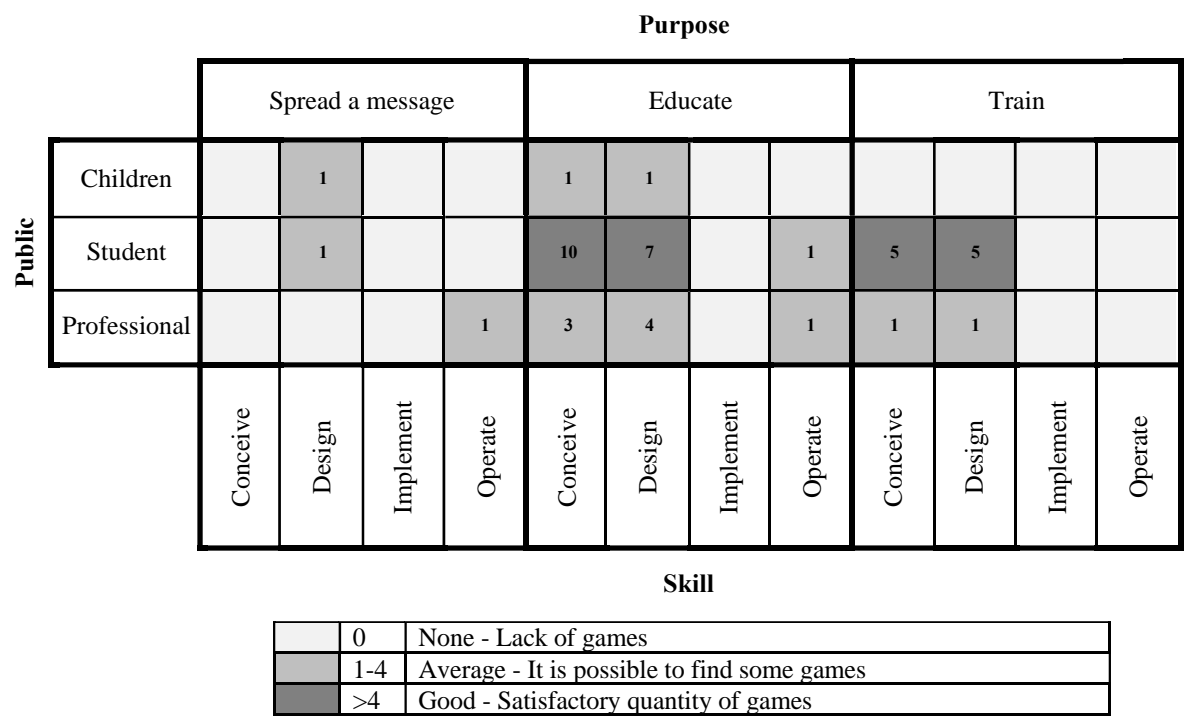

Figure 1. Taxonomy of different serious games

For example, the Eco-Board Game (Boks and McAloone, 2009), where participants have to design a board game to learn sustainable products design, has been classified in the boxes "Children", "Student" and "Professional" for the public category, "educate" and "train" for the purpose category and "conceive" and "design" groups of the skills category. In the same way, the Smart City Game (Zhuang al., 2017), whose purpose is to communicate about smart city has been classified in the boxes "children" and "student" for the public category, "Design" for the purpose category and "spread a message" for the skills category.

In figure 1, one can see that there are few games about creativity and innovation for children compared to students and professionals. Therefore, this article presents a new game to give children a first 'handson experience" on creativity and innovation techniques.

\section{PROPOSITIONS OF A NEW GAME}

To design this new game, we used the Serious Game Design Assessment (SGDA) framework that was designed to help designers transform traditional educational supports into serious board games for teaching Innovation Processes (Ma et al., 2019). The SGDA is composed of 6 items: Game purpose, Content \& Information, Mechanics, Fiction \& Narrative, Aesthetics \& Graphics and Framing.

The goal of the serious game presented in this paper is to teach to children a generic innovation process with some creativity techniques. The innovation process used is adapted to the one of Markou et al (2017). It is composed of 7 steps that can be merged in 4 blocks: introduction, divergent phase, convergent phase and wrap-up (Figure 2). Before the start of the game, child groups must be composed by a facilitator (teacher, parent, adult) and the game objective explicitly stated.



Figure 2. Game progress 




Figure 3. Components of the "Lino" game

The board game created is centred on a fox character called "Lino". Figure 3 shows its 6 components: game board (A), rules (B), dream cards (C), pawn (D), drawing book (E) and innovation trick cards (F). The game board (A) is composed of 7 boxes representing the 7 steps of the game. The playing children, in group of 4 or 5, join Lino, a small fox (D) during a full day and help him transforming a dream in a more concrete idea. An adult supervises the children and used the game rules sheet (B) to understand the game.

- Step 1: Lino wakes up and dreamed of an innovative object: The group of children chooses a dream card (C) where an idea is described. For example, an ultralight schoolbag.

- Step 2: Lino arrives at school and tries to describe his ideas to his friends: each child of the group describes and draws their first ideas in a time of 10 minutes and share them with the other group members.

- Step 3: Lino comes back to class and explains his idea to the teacher that gives him a trick card to help him: Children explain their ideas to their supervisor. Then, the group choose a trick card $(\mathrm{F})$ and try to understand it with their supervisor. For example, the inversion technique is explained in one of these cards. It consists of seeking, by analogy, solutions that aim at the opposite objective of the initial problem.

- Step 4: Lino finds his friends in the canteen and use the trick card to get new ideas: children follow the trick card and use it to describe or draw new ideas in a time of $15 \mathrm{~min}$.

- Step 5: Lino goes home and takes tea with his friends to help him choose a single idea: in a time of 5 min, children define the disadvantages and benefits of each of their ideas and choose the best one.

- Step 6: Lino tells his parents his journey throughout the day and draws in the "big book of invention" his best idea: children describe and draw them in their invention book (E).

- Step 7: Lino goes to sleep and dreams about its day: children remember their day and exchange 
with the supervisor on the innovative process used.

The next part presents a case study to evaluate this game with children. It will permit to evaluate for example if the game is the game suitable for a school environment or well adapted to the chosen age group.

\section{CASE STUDY}

The experiment was done twice in November 2018 in a primary school in Levallois, a city in France. One in a class of 25 pupils in third grade ( $~ 8$ years old) and one in a class of 24 pupils in fifth grade ( $\sim 10$ years old). In each case, children are grouped by 4 or 5 . Two supervisors (their teachers) help them to launch the dynamic, to time the different steps and to refocus the debates if it is necessary. Children are free to express all their ideas, with their own words. There are no good or bad answers during this game. During the drafting stages, spelling or conjugation errors were not a problem.

At the end of the game, children had to individually answer to 9 questions with a 3-point Likert scale from a sad face $:)$ to a happy face $: ;$ and 3 qualitative questions. These questions are meant to determine if the children had fun and enjoy the game (Q1. Did you have fun? Q2. Did you like filling the "big book of invention"? Q3. Were you satisfied with your invention? Q4. Would you like to build your invention for real? Q5. Do you want to play again?) if the educational goal was achieved (Q6. Did you understand the used process? Q7. Did you understand the method card?) and if the design game was fine (Q8. Where the explanations clever enough? Q9. Did you like the game's design?). The two supervisors had also to answer three qualitative questions to determine if the game was or wasn't suited for their tutoring and why, if they appreciated the activity and if they would be inclined to include this game in their future lessons.

Results are presented in the next section. For each question for both children populations, bar charts are presented. Results have been normalized to have values comprise between 0 and 1 .

\section{RESULTS}

Figure 4 presents one of the experiments with the 24 fifth-grade children. In this picture, one can see that the children are grouped by 4 or 5 , and that supervisors (their teachers) are helping them.

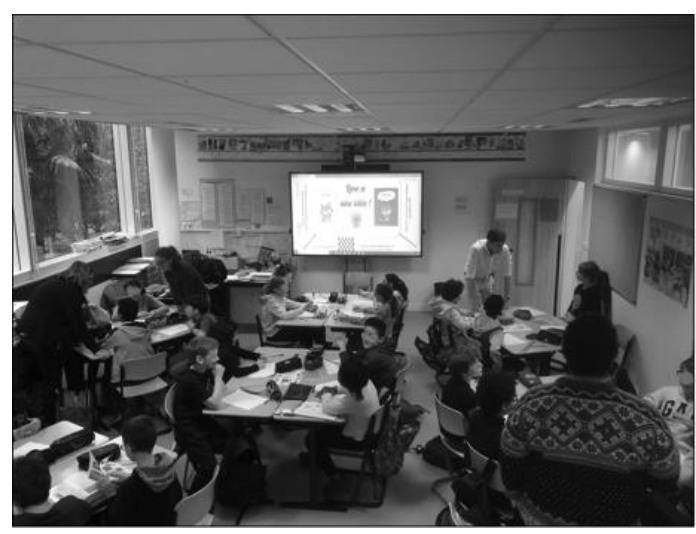

Figure 4. Photography taken with the fifth-grade children

\subsection{Quantitative results}

The following graph describes the results of the nine questions for the third-grade children. For each group, the normalized mean and the Standard Deviation (SD) are presented.

Figure 5 shows a distinction between the ludic aspect of the game and its "serious" part. In fact, both population of children said they had a lot of fun (Q1) (mean_3rd =0,92, SD_3rd =0,18), (mean_5th = 0,92, SD_5th $=0,24)$. In the same way, they said they liked drawing in the "big book of invention" (Q2), were satisfied of their invention (Q3), wanted to play again (Q5) and wanted to realize their invention in the real world (Q5) (means > 0,78). Concerning the game design, a good score was given by both ages (Q9) (mean_3rd =0,79, SD_3rd =0,32), (mean_5th $=0,80, S_{-}$5th $=0,32$ ). The gave explanations (Q8) were rated in the same way. However, concerning the understanding of the different steps of the game (Q6), a lower score was given (mean_3rd =0,67, SD_3rd $=0,31)$, (mean_5th $=0,72, \mathrm{SD}=0,33$ ). The understanding of the trick cards $(\mathrm{Q} 7)$ has also a low score (mean $<0,63)$. 


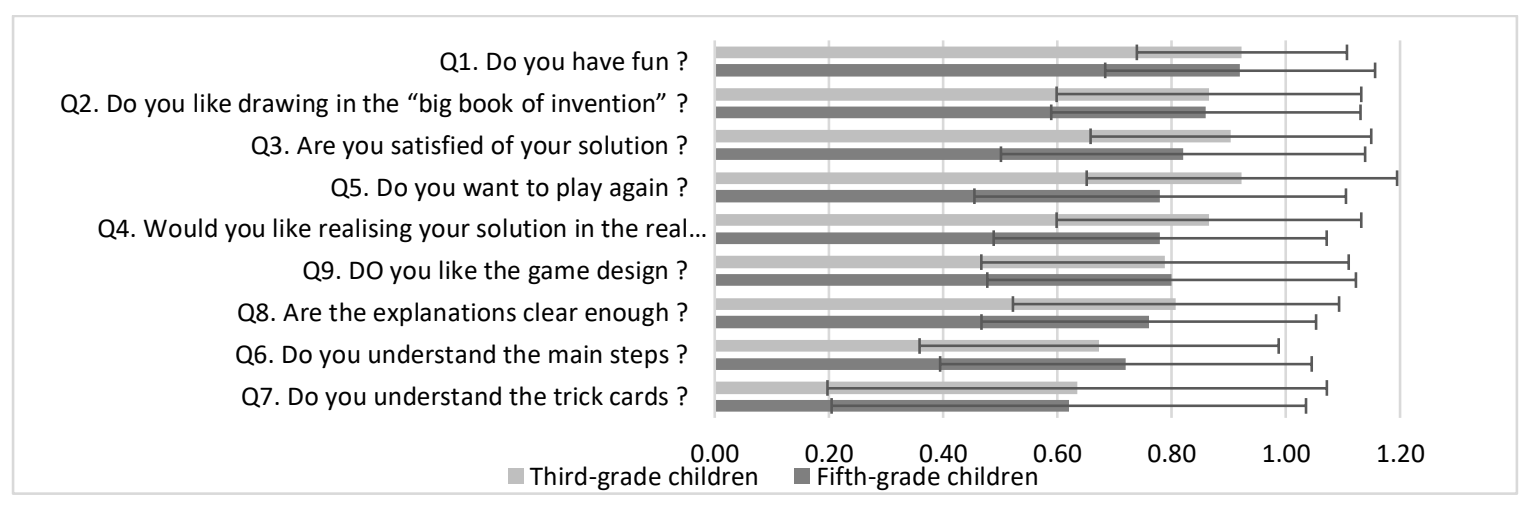

Figure 5. Results in both population of children (3rd and 5th grade)

We realized a student t-test to compare the two populations of children. It shows no significant differences between the third-grade students and the fifth-grade students for each question (Student's ttest, $\mathrm{p}>0.10)$.

\subsection{Qualitative results}

We also gathered the results of their inventions with the "Big book of Invention". We notice that the younger participants from the third-grade class drew more unrealistic and innovative things that the fifth-grade students. The draws of the older students seem to be more inspired by existing products and systems.

We consider the realistic dreams as solutions which are inspired by existing systems or are like real products. Instead of fanciful draws which are based on new theories and no similar systems exists in real life.

\begin{tabular}{|l|c|c|}
\hline & Realistic draws & Fanciful draws \\
\hline Third Grade & 0 & 6 \\
\hline Fifth Grade & 5 & 1 \\
\hline Total & 5 & 7 \\
\hline
\end{tabular}

Figure 6. Comparative table between third and fifth grade's draws

For example, the following "Bigbook of Invention" was filled by third grade students (figure 7), their invention is an electric bag which can "help the user to find everything quickly".

In the solution, all functions to find components are related with electric connections and help the user to find the different devices. The new idea is the use of a grid card where components are listed, this is an innovative solution not inspired by existing products.

Most children wanted to play again and enjoyed the game. The third-grade students had fewer barriers regarding ideas (less realistic, more imaginary) and drawings than the fifth-grade students. These ones had to be more motivated to produce drawings. They wanted to realize more realistic ideas. Concerning the innovation method, both groups have difficulties in understanding the trick cards and the process in the amount of time available. They had issues of vocabulary.

Educators stated that a preparation time prior to the game would be needed to ensure a deeper understanding of the rules and the trick cards. They enjoyed the creativity and the reflexion process needed to play the game. For them, the game is well suited for an educational purpose in a class. The educator was convinced by the game which also encourage children to discuss, exchange and use arguments to support their ideas. Furthermore, they are convinced that the game is good for the development of team working and collective decision making.

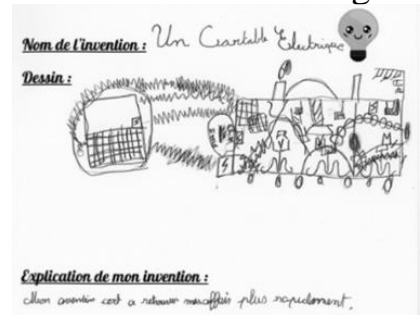

Figure 7. Solution of "an electric bag to easily find everything" presented by a group of third grade students 


\section{CONCLUSION AND PERSPECTIVES}

In this article, we present a new game to answer the need to develop serious game to enhance the creativity and innovation of children. The game created meets most of its expectations: the children had fun and were willing to play again. The game allows the children to use creativity, to make improvements on their solutions, to work as a team, to discuss and argue to take collective decisions. However, work must be done on its "serious part", i.e., to transmit knowledge on creativity and innovation. The game could be organized in two parts: a lesson on the notions dealt with and examples to illustrate them in the morning and the game as an application in the afternoon. This should have the benefit to increase the autonomy of the children during the game. In perspective, further game design must be done to make a board game clearer and to make the trick cards easier to understand. This step can also help the children to find real innovative solutions which are disrupted with the current systems, it is important to push them to explore new ideas, without limits. We plan next to develop and test this improved game version with other French and international.

\section{ACKNOWLEGEMENT}

We thank Isabelle Courbois, teacher in third grade, and Anne Moussavian, teacher in fifth grade, who accepted to test the serious game in their class in Levallois and for children and teacher feedbacks. We also thank Leïla Auger and Fanny Clément who co-created this serious game.

\section{REFERENCES}

[1] Boks, C. and Mcaloone, T. (2009). The design of Eco Board Games as an umbrella approach to sustainable product design education, Global Engineering Alliance for Research and Education (GEARE)-A Comprehensive Study \& Intern Abroad Program for Engineering Students.

[2] Breuer, J. and Bente, G. (2010). Why so serious? On the relation of serious games and learning. Journal for Computer Game Culture, 4 (1), pp.7-24

[3] Cortes Sobrino, A. Bertrand, M., Di Domenico, E., Jean, C. and Maranzana, N. (2017). Educational Games for Design and innovation: Proposition of a new taxonomy to identify perspectives of development. $21^{\text {st }}$ International Conference on Engineering Design (ICED17), Vancouver, Canada.

[4] Crawley, E. F. (2002). Creating the CDIO syllabus, a universal template for engineering education. Frontiers in Education, 2002. FIE 2002. 32nd Annual.

[5] Djaouti D., Alvarez J., Jessel J.-P. and Rampnoux O. (2011). Origins of Serious Games. In: Ma M., Oikonomou A., Jain L. (eds) Serious Games and Edutainment Applications. Springer, London

[6] Djouti, D., Alvarez, J. and Jessel, J.-P. (2011). Classifying serious games: the G/P/S model. Handbook of research on improving learning and motivation through educational games: Multidisciplinary approaches, 118-136.

[7] Ma, Y., Vallet, F., Cluzel, F. and Yannou, B. (2019). Analysing the Relevance of Serious Game Elements for Effectively Teaching Innovation Processes. $22^{\text {nd }}$ International Conference on Engineering Design (ICED19), Delft, The Netherlands.

[8] Markou, F., Segonds, F., Rio, M. and Perry, N. (2017). A methodological proposal to link Design with Additive Manufacturing to environmental considerations in the Early Design Stages International Journal on Interactive Design and Manufacturing (IJIDeM) - Vol. 11, n4, p.799812

[9] Michael, D. R. and Chen, S. L. (2005). Serious games: Games that educate, train, and inform. Muska \& Lipman/Premier.

[10] Susi, T., Johannesson, M. and Backlund, P. (2007). Serious games: An overview.

[11] Zhuang, R., Fang, H., Zhang, Y., Lu, A. and Huang, R. (2017). Smart learning environments for a smart city: from the perspective of lifelong and lifewide learning. Smart Learning Environments, 4(6). 